\title{
Solubility in Binary Solvent Mixtures: Anthracene Dissolved in Alcohol + 2-Methyl-1-butanol Mixtures at $298.2 \mathrm{~K}$
}

\author{
Cassandra I. Monárrez, Priscilla G. Taylor, Anh M. Tran, and William E. Acree, J r.* \\ Department of Chemistry, P.O. Box 305070, University of North Texas, Denton, Texas 76203-5070
}

\begin{abstract}
Experimental solubilities are reported for anthracene dissolved in seven binary alcohol +2 -methyl-1butanol solvent mixtures at $25^{\circ} \mathrm{C}$. The al cohol cosolvents studied were 1-propanol, 2-propanol, 1-butanol, 2-butanol, 2-methyl-1-propanol, 3-methyl-1-butanol, and 2-pentanol. Results of these measurements are used to test a mathematical representation based upon the combined nearly ideal binary solvent (NIBS)/ Redlich-Kister equation. For the seven systems studied, the combined NIBS/Redlich-Kister equation was found to mathematically describe the experimental data to within an overall average absolute deviation of approximately $\pm 0.4 \%$.
\end{abstract}

\section{Introduction}

Solid-liquid equilibrium data of organic nonelectrolyte systems are becoming increasingly important in the petroleum industry, particularly in light of present trends toward heavier feedstocks and known carcinogenicity/ mutagenicity of many of the larger polycyclic aromatic compounds. Solubility data for a number of polycyclic aromatic hydrocarbons (i.e., anthracene and pyrene) and heteroatom polynuclear aromatics (i.e., carbazole, dibenzothiophene, and xanthene) have been published in the recent chemical literature (for a listing of references, see refs $1-3$ ). Despite efforts by experimentalists and scientific organizations, both in terms of new experimental measure ments and critically evaluated data compilations, it is not feasible to experimentally measure solubilities in every possible binary and ternary solvent mixture that might be encountered in pharmaceutical and engineering applications.

Recognizing this fact, researchers have turned to predictive methods as a means to generate desired quantities. Numerous equations have been suggested for predicting solute solubilities in binary solvent mixtures. For the most part, the predictive methods do provide fairly reasonable estimates for noncomplexing systems. There still remains, however, the need to devel op better predictive expressions and mixing models to describe the more nonideal complexing systems believed to contain hydrogen bonding solvent components. Continued development of solution models for describing the thermodynamic properties of a solute in binary solvent systems requires that a large database be available for assessing the applications and limitations of derived expressions. Currently, only a limited database exists for crystalline nonelectrolyte solubility in binary solvent mixtures. For this reason, anthracene solubilities were determined in seven binary alcohol +2 -methyl-1butanol solvent mixtures. Results of these measurements are used to further test the descriptive ability of the combined nearly ideal binary solvent (NIBS)/RedlichKister equation.

* To whom correspondence should be addressed. E-mail: acree@unt.edu.

\section{Experimental Methods}

Anthracene (Aldrich, 99\%) was recrystallized three times from acetone. 1-Propanol (Aldrich, 99+\%, anhydrous), 2-propanol (Aldrich, 99+\%, anhydrous), 1-butanol (Aldrich, HPLC, 99.8+\%), 2-butanol (Aldrich, 99+\%, anhydrous), 2-methyl-1-propanol (Aldrich, 99.5\%, anhydrous), 3-methyl1-butanol (Aldrich, 99+\%, anhydrous), 2-pentanol (Acros, 99+\%), and 2-methyl-1-butanol (Aldrich, 99+\%) were stored over molecular sieves and distilled shortly before use. Gas chromatographic analysis showed solvent purities to be $99.7 \mathrm{~mol} \%$ or better. Binary solvent mixtures were prepared by mass so that compositions could be calculated to 0.0001 mole fraction.

Excess solute and solvent were placed in amber glass bottles and allowed to equilibrate in a constant temperature water bath at $(25.0 \pm 0.1){ }^{\circ} \mathrm{C}$ with periodic shaking for at least 3 days (often longer). Attainment of equilibrium was verified both by repetitive measurements after a minimum of 3 additional days and by approaching equilibrium from supersaturation by pre-equilibrating the solutions at a higher temperature. Aliquots of saturated anthracene solutions were transferred through a coarse filter into a tared vol umetric flask to determine the amount of sample and diluted quantitatively with methanol for spectrophotometric analysis at $356 \mathrm{~nm}$ on a Bausch and Lomb Spectronic 2000. Concentrations of the dilute solutions were determined from a Beer-Lambert law absorbance versus concentration working curve derived from measured absorbances of standard solutions of known molar concentrations. Apparent molar absorptivities, $\epsilon$, of the nine standard solutions varied systematically with molar concentration and ranged from approximately $\epsilon /(\mathrm{L}$

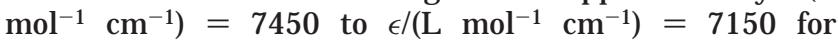
anthracene concentrations ranging from $\mathrm{C} / \mathrm{M}=6.75 \times 10^{-5}$ to $C / M=2.25 \times 10^{-4}$. Identical molar absorptivities were obtained for select anthracene standard solutions that contained up to $5 \mathrm{vol} \%$ of the neat alcohol cosolvents. Experimental anthracene solubilities in the seven binary alcohol + 2-methyl-1-butanol solvent mixtures are listed in Table 1. Numerical values represent the average of between four and eight independent determinations, with the measured values being reproducible to within $\pm 1.0 \%$. 
1342 J ournal of Chemical and Engineering Data, Vol. 48, No. 5, 2003

Table 1. Experimental Mole Fraction Solubilities of Anthracene $\left(x_{A}^{\text {sat }}\right)$ in Binary Alcohol $(B)+$ 2-Methyl-1-butanol (C) Solvent Mixtures at $25.0^{\circ} \mathrm{C}$

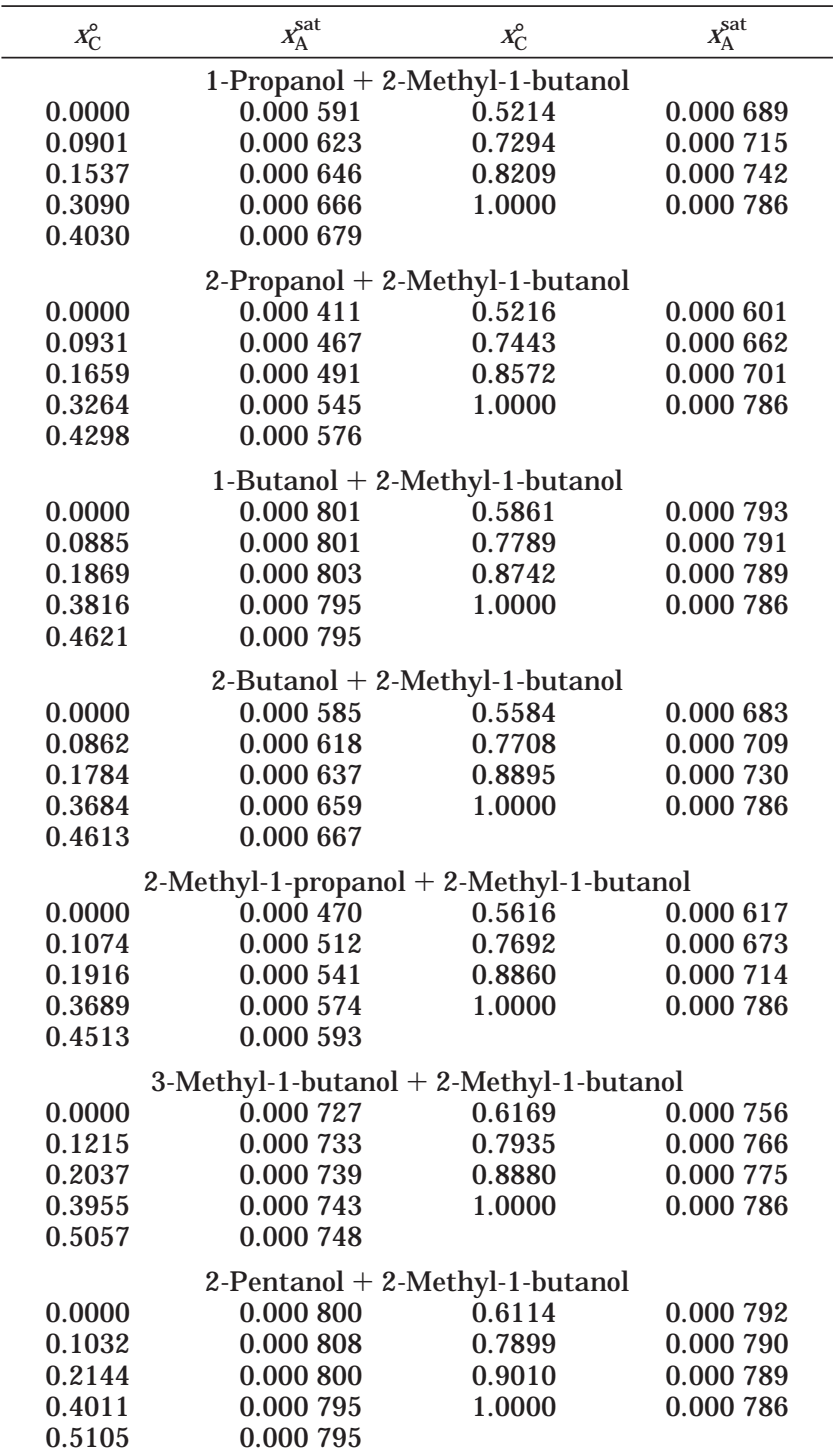

\section{Results and Discussion}

Acree and co-workers ${ }^{4-6}$ suggested the combined NIBS/ Redlich-Kister model

$$
\ln x_{A}^{\text {sat }}=x_{B}^{\circ} \ln \left(x_{A}^{\text {sat }}\right)_{B}+x_{C}^{\circ} \ln \left(x_{A}^{\text {sat }}\right)_{C}+x_{B}^{\circ} x_{C}^{\circ} \sum_{i=0}^{N} S_{i}\left(x_{B}^{\circ}-x_{C}^{\circ}\right)^{i}
$$

as a possible mathematical representation for describing how the experimental isothermal solubility of a crystalline solute dissolved in a binary solvent mixture varies with binary solvent composition. In eq $1 x_{B}^{\circ}$ and $x_{C}^{\circ}$ refer to the initial mole fraction composition of the binary solvent cal culated as if solute (A) were not present, $\mathrm{N}$ is the number of curve-fit parameters used, and $\left(x_{A}^{\text {sat }}\right)_{i}$ is the saturated mole fraction solubility of the solute in pure solvent $\mathrm{i}$. The various $S_{i}$ "curve-fit" parameters can be evaluated via leastsquares analysis as discussed elsewhere. ${ }^{7}$

The combined NIBS/Redlich-Kister equation has been shown to provide very accurate mathematical representations of anthracene, pyrene, and carbazole solubilities in a large number of both complexing and noncomplexing solvent mixtures. ${ }^{1-3}$ J ouyban-Gharamaleki and coworkers ${ }^{8-11}$ successfully used the volume fraction, $\phi_{\mathrm{i}}$, modification of eq 1

$$
\ln x_{A}^{\text {sat }}=\phi_{B}^{\circ} \ln \left(x_{A}^{\text {sat }}\right)_{B}+\phi_{C}^{\circ} \ln \left(x_{A}^{\text {sat }}\right)_{C}+\phi_{B}^{\circ} \phi_{C}^{\circ} \sum_{i=0}^{N} S_{i}\left(\phi_{B}^{\circ}-\phi_{C}^{\circ}\right)^{i}
$$

to describethe sol ubility behavior of various drug mol ecules in binary aqueous-organic solvent mixtures. In the pharmaceutical industry, researchers often express the solvent composition in terms of volume fractions, rather than in terms of mole fractions. In the case of structurally similar drug molecules, the numerical values of the $S_{i}$ coefficients were found to be nearly constant in a given binary solvent mixture. ${ }^{11}$ More recently, Deng et al. ${ }^{12-14}$ and Pribyla et al. ${ }^{15-17}$ have shown that the $S_{i}$ coefficients determined by regressing experimental anthracene data in binary alkane + alkane, alkane + alcohol, alcohol + alcohol, alcohol + ether, and alkane + ether solvent mixtures allow one to predict anthracene solubilities in ternary alkane + alkane + alcohol, alkane + alcohol + alcohol, and alkane + alcohol + ether solvent mixtures. The predictive expression for the ternary solvent mixture is

$$
\begin{array}{r}
\ln x_{A}^{\text {sat }}=x_{B}^{\circ} \ln \left(x_{A}^{\text {sat }}\right)_{B}+x_{C}^{\circ} \ln \left(x_{A}^{\text {sat }}\right)_{C}+x_{D}^{\circ} \ln \left(x_{A}^{\text {sat }}\right)_{D}+ \\
x_{B}^{\circ} x_{C}^{\circ} \sum_{i=0}^{r} S_{i, B C}\left(x_{B}^{\circ}-x_{C}^{\circ}\right)^{i}+x_{B}^{\circ} x_{D}^{\circ} \sum_{j=0}^{S} S_{j, B D}\left(x_{B}^{\circ}-x_{D}^{\circ}\right)^{j}+ \\
x_{C}^{\circ} x_{D}^{\circ} \sum_{k=0}^{t} S_{k, C D}\left(x_{C}^{\circ}-x_{D}^{\circ}\right)^{k}
\end{array}
$$

a mole fraction average of the logarithmic solute solubilities in the three pure solvents $\left[\left(x_{A}^{\text {sat }}\right)_{B},\left(x_{A}^{\text {sat }}\right)_{C}\right.$, and $\left.\left(x_{A}^{\text {sat }}\right)_{D}\right]$ plus a Redlich-Kister summation term for each solvent pair. The documented success ${ }^{11-16}$ of eq 3 in predicting anthracene solubilities in more than 60 different ternary solvent systems ill ustrates the need for measured solute sol ubilities in binary solvent mixtures.

In the chemical and pharmaceutical literature, different mathematical expressions can be found for describing how the measured solute solubility varies with binary solvent composition (see refs 8-11). For many of the published mathematical representations the equations are limited to binary solvent systems. The calculated equation coefficients cannot be used to predict the solubility of the solute in ternary solvent mixtures. This is not the case with the combined NIBS/Redlich-Kister equation. Equation coefficients determined by curve-fitting the measured solute solubility data in accordance with eq 1 can be used to predict solubilities in ternary solvent mixtures through eq 3. It is hoped that as additional solubility data become available for solutes dissolved in ternary solvent mixtures, researchers will apply many of the previously published equations for describing solute solubilities in binary solvent systems to ternary and higher-order multicomponent solvent systems.

The ability of eq 1 to mathematically represent the experimental solubility of anthracene in the seven binary alcohol + 2-methyl-1-butanol mixtures is summarized in Table 2 in the form of "curve-fit" parameters, that were obtained by regressing the measured mole fraction solubility data (see Table 1) in accordance with eq 1 , and the percent deviations in back-calculated solubilities. Two of the binary solvent systems, 1-butanol +2 -methyl-1-butanol and 2-pentanol +2 -methyl-1-butanol, did not require any curve-fit parameters. Each percent deviation is based upon the measured anthracene solubility data at the seven different binary solvent compositions. Careful examination 
Table 2. Mathematical Representation of Anthracene Solubilities in Several Binary Alcohol (B) + 2-Methyl-1-butanol (C) Solvent Mixtures by Eq 1

\begin{tabular}{|c|c|c|}
\hline \multirow[b]{2}{*}{ binary solvent system $(B+C)$} & \multicolumn{2}{|c|}{ eq 1} \\
\hline & $\mathrm{S}_{\mathrm{i}}^{\mathrm{a}}$ & $\% \operatorname{dev}^{b}$ \\
\hline 1-propanol + 2-methyl-1-butanol & $\begin{array}{l}0.031 \\
0.267 \\
0.174\end{array}$ & 0.3 \\
\hline 2-propanol + 2-methyl-1-butanol & $\begin{array}{l}0.154 \\
0.509 \\
0.162\end{array}$ & 0.7 \\
\hline $\begin{array}{l}\text { 1-butanol + 2-methyl-1-butanolc } \\
\text { 2-butanol + 2-methyl-1-butanol }\end{array}$ & $\begin{array}{r}-0.040 \\
0.433 \\
0.021\end{array}$ & $\begin{array}{l}0.2 \\
0.7\end{array}$ \\
\hline 2-methyl-1-propanol + 2-methyl-1-butanol & $\begin{array}{r}-0.024 \\
0.423\end{array}$ & 0.4 \\
\hline 3-methyl-1-butanol + 2-methyl-1-butanol & $\begin{array}{r}-0.034 \\
0.035\end{array}$ & 0.2 \\
\hline 2-pentanol + 2-methyl-1-butanolc & & 0.4 \\
\hline
\end{tabular}

a The combined NIBS/Redlich-Kister curve-fit parameters are ordered as $\mathrm{S}_{0}, \mathrm{~S}_{1}$, and $\mathrm{S}_{2} .{ }^{\mathrm{b}}$ Deviation $(\%)=(100 / \mathrm{N}) \sum \mid\left[\left(\mathrm{x}_{\mathrm{A}}^{\text {sat }}\right)^{\text {calc }}-\right.$ $\left.\left(x_{A}^{\text {sat }}\right)^{\exp }\right] /\left(x_{A}^{\text {sat }}\right)^{\exp } \mid$. ' E quation 1 accurately described the measured anthracene solubility data without the use of curve-fit parameters.

of Table 2 reveals that eq 1 provided a fairly accurate mathematical representation for how the solubility of anthracene varies with solvent composition. Deviations between the experimental mole fraction solubilities and back-calculated values based upon eq 1 differed by an overall average absolute deviation of about $\pm 0.4 \%$.

\section{Literature Cited}

(1) Acree, W. E., J r. Polycyclic Aromatic Hydrocarbons in Pure and Binary Solvents; Volume 54 in IUPAC Solubility Data Series; Oxford University Press: Oxford, U.K., 1994.

(2) Acree, W. E., J r. Polycyclic Aromatic Hydrocarbons: Binary Nonaqueous Systems: Part 1 (Solutes A-E); Volume 58 in IUPAC Solubility Data Series; Oxford University Press: Oxford, U.K., 1995.

(3) Acree, W. E., J r. Polycyclic Aromatic Hydrocarbons: Binary Nonaqueous Systems: Part 2 (Solutes F-Z); Volume 59 in IUPAC Solubility Data Series; Oxford University Press: Oxford, U.K., 1995.

(4) Acree, W. E., J r. Mathematical Representation of Thermodynamic Properties. Part 2. Derivation of the Combined Nearly Ideal Binary Solvent (NIBS)/Redlich-Kister Mathematical Representa- tion from a Two-Body and Three-Body Interactional Mixing Model. Thermochim. Acta 1992, 198, 71-79.

(5) Acree, W. E., J r.; McCargar, J . W.; Zvaigzne, A. I.; Teng, I.-L. Mathematical Representation of Thermodynamic Properties. Carbazole Solubilities in Binary Alkane + Dibutyl Ether and Alkane + Tetrahydropyran Solvent Mixtures. Phys. Chem. Liq. 1991, 23, 27-35.

(6) Acree, W. E., J r.; Zvaigzne, A. I. Thermodynamic Properties of Nonelectrolyte Solutions. Part 4. Estimation and Mathematical Representation of Solute Activity Coefficients and Solubilities in Binary Solvents Using the NIBS and Modified Wilson Equation. Thermochim. Acta 1991, 178, 151-167.

(7) Fletcher, K. A.; Pandey, S.; McHale, M. E. R.; Acree, W. E., J r. Solubility of benzil in (binary alcohol +1 -octanol) solvents. J . Chem. Thermodyn. 1997, 29, 475-480.

(8) J ouyban-Gharamaleki, A.; Clark, B.J .; Acree, W. E., J r. Prediction of Drug Solubility in Ternary Solvent Mixture. Drug Dev. Ind. Pharm. 2000, 26, 971-973.

(9) J ouyban-Gharamaleki, A.; Acree, W. E.,J r. Comparison of Models for Describing Multiple Peaks in Solubility Profiles. Int. J . Pharm. 1998, 167, 177-182.

(10) J ouyban-Gharamaleki, A.; Hanaee, J . A Novel Method for Improvement of the CNIBS/R-K Equation. Int. J . Pharm. 1997, 154, $243-245$.

(11) J ouyban-Gharamaleki, A.; Barzegar-J alali, M.; Acree, W. E., J r. Solubility Correlation of Structurally Related Drugs in Binary Solvent Mixtures. Int. J . Pharm. 1998, 166, 205-209.

(12) Deng, T.; Childress, S. D.; De Fina, K. M.; Sharp, T. L.; Acree W. E., J r. Solubility of Anthracene in Ternary Propanol + Butano + 2,2,4-Trimethyl pentane Solvent Mixtures. J . Chem. Eng. Data 1998, 43, 1065-1067.

(13) Deng, T.; Childress, S. D.; De Fina, K. M.; Acree, W. E., J r. Solubility of Anthracene in Ternary Propanol + Butanol + Heptane Solvent Mixtures. Chem. Eng. Commun. 1999, 172, 217224.

(14) Deng, T. Thermodynamic Properties of Nonelectrolyte Solutes in Ternary Solvent Mixtures. Ph.D. Dissertation, University of North Texas, 1999.

(15) Pribyla, K. J .; Ezell, C.; Van, T. T.; Acree, W. E., J r. Solubility of Anthracene in Ternary Methyl tert-Butyl Ether + Alcohol + 2,2,4Trimethylpentane Solvent Mixtures at 298.15 K.J . Chem. Eng. Data 2000, 45, 974-976.

(16) Pribyla, K.J .; Chuca, I.; Van, T. T.; Acree, W. E., J r. Solubility of Anthracene in Ternary Methyl tert-Butyl Ether + Alcohol + Heptane Solvent Mixtures at 298.15 K. J . Chem. Eng. Data 2000, 45, 533-535.

(17) Pribyla, K. J. Thermochemical Study of Crystalline Solutes Dissolved in Ternary Hydrogen-Bonding Solvent Mixtures. Ph.D. Dissertation, University of N orth Texas, 2001.

Received for review May 5, 2003. Accepted J uly 4, 2003. This research was supported in part by the University of North Texas Research Council.

J E030175Z 